\title{
A RIQUEZA FORMAL EM POEMAS REUNIDOS, DE ANTONIO BRASILEIRO - UMA INTRODUÇÃO
}

\author{
Fabrício Lima Oliveira (IC/UEFS). ${ }^{1}$ \\ Roberval Alves Pereira (Orientador/UEFS). ${ }^{2}$
}

\section{RESUMO}

O presente artigo sobre o livro Poemas Reunidos, de Antonio Brasileiro, apresenta uma apurada reflexão lírico-filosófica. Brasileiro, com sua multifacetada poesia, retrata, de muitas maneiras e em muitas dimensões, a instabilidade e a fragilidade da condição humana. Para dar conta de tudo isso, o poeta evidencia o domínio de muitas áreas de conhecimento e a capacidade de encontrar soluções formais para as mais diversas situações existenciais encenadas em seus poemas. Neste sentido, não hesita em lançar mão, por exemplo, do mais puro lirismo, ou, ao contrário, do exagero cômico, do grotesco, da ironia, da sátira e do desconcertante humor que the é característico, muitas vezes obtido pela rara capacidade de utilização do paradoxo, que põe em cheque a mera racionalidade, gerando choque e surpresa.

Palavras-chave: Antonio Brasileiro; Riqueza formal; Musicalidade.

${ }^{1}$ Graduando do Curso de Licenciatura em Letras Vernáculas na Universidade Estadual de Feira de Santana - UEFS, e-mail: oliverletras01@gmail.com

${ }^{2}$ Professor Orientador: Dr. em Teoria e História Literária pela Universidade Estadual de Campinas, Professor Pleno de Literatura na Universidade Estadual de Feira de Santana - UEFS, e-mail: robervalpereyr@gmail.com 


\section{INTRODUÇÃO}

Antonio Brasileiro (Antonio Brasileiro Borges), poeta, ensaísta, artista plástico e professor, nasceu em 15 de Junho de 1944 em Matas do Orobó, Bahia. Reside atualmente em Feira de Santana. Eleito em 08/06/2009 para a Academia de Letras da Bahia, é o primeiro escritorresidente no interior do estado a assumir uma Cadeira na referida Academia, ocupando a cadeira de Zélia Gattai. Antonio Brasileiro é um dos mais consistentes poetas brasileiros, na contemporaneidade. Sua poesia é instigante e evidencia-se, entre outras coisas, pelo rigor formal e pela utilização e domínio de uma gama muito variada de recursos técnicos.

Na década de 1960 - entre os quinze e vinte e cinco anos - o poeta, já residente em Salvador, vive uma vida intensa: entra para a Universidade (Ciências Sociais, UFBA), passa a estudar no Seminário de Música, além disso, começa a pintar, publica seus primeiros livros, cria as Edições Cordel (Revistas Serial e Cordel). Reside por algum tempo no Rio de Janeiro e em Belo Horizonte (1966/67) e têm poemas publicados na Revista Civilização Brasileira. No início de 1971, passa a morar em Feira de Santana, onde cria a revista Hera (1972 - 2005) em parceria com os alunos seus do Colégio Estadual de Feira de Santana, a exemplo de Roberval Pereyr, Washington Queiroz e Wilson Pereira de Jesus. Hera, que em seus três primeiros números era uma revista de contos, a partir do número 4 passou a publicar apenas poesia (e, como tal, contando, a partir daí, com a participação de nomes como, entre outros, Juraci Dórea, Iderval Miranda, Luís Valverde ,Luis Pimentel, Edmundo Carôso (Edmundo) e Carlos Pitta (Piter),Trazíbulo Henqique Pardo Casas, Rubens Alves Pereira, Assis Freitas Filho, além dos três cofundadores acima citados), engendrou, sob a coordenação inicial de Antonio Brasileiro, uma marcante movimentação literáriocultural na Bahia, com significativa repercussão nacional.

Alguns anos depois (1980), sai pela Editora Civilização Brasileira o primeiro livro de poesia de Antonio Brasileiro em edição nacional, intitulado Os três movimentos da sonata. Em 1992, Brasileiro conclui seu Mestrado em Letras pela UFBA, e liga-se, como professor, à Universidade Estadual de Feira de Santana-UEFS (1993). Anos depois, conclui Doutorado em Literatura Comparada (UFMG, 1999). Antonio 
Brasileiro, como pintor, está entre os da chamada Geração 70 de artistas plásticos da Bahia.

Com quase 30 livros publicados, destacam-se entre eles: Caronte (1995, romance), Antologia poética (1996), A estética da sinceridade (2000, ensaios), Da inutilidade da poesia (2002, ensaio), Poemas reunidos (2005), Dedal de areia (2006, poesia), Desta varanda( ), Longes terras ( ) e Lisboa 1935( ).

O poeta Antonio Brasileiro apresenta na sua obra uma apurada reflexão líricofilosófica. Sua multifacetada poesia retrata, de muitas maneiras e em muitas dimensões, a instabilidade e a fragilidade da condição humana. Para dar conta de tudo isso, o poeta evidencia o domínio de muitas áreas de conhecimento e a capacidade de encontrar soluções formais para as mais diversas situações existenciais encenadas em seus poemas. Neste sentido, não hesita em lançar mão, por exemplo, do mais puro lirismo, ou, ao contrário, do exagero cômico, do grotesco, da ironia, da sátira e do desconcertante humor que lhe é característico, muitas vezes obtido pela rara capacidade de utilização do paradoxo, que põe em cheque a mera racionalidade, gerando choque e surpresa. Tudo isso sem perder jamais de vista a dimensão estética da linguagem, evidenciada através da utilização (e da combinação) sempre oportuna e surpreendente do ritmo, da imagem e da musicalidade.

Em seguida, passaremos a considerar alguns poemas de Antonio Brasileiro publicados em Poemas reunidos, reunião de livros editados em 2005 pela Fundação Cultural do Estado da Bahia. Nesses poemas tentaremos evidenciar alguns aspectos da riqueza formal do autor, tendo em vista, pelo menos em parte (já que no âmbito de um simples artigo não poderíamos dar conta do que aqui se constata sobre a produção poética do autor), as colocações feitas acima neste sentido. Assim, neste artigo, tentaremos apenas oferecer uma amostra do que pretendemos, em projeto futuro, trabalhar na Poemas reunidos, de Brasileiro. 


\title{
2. LOUCURA E POESIA
}

Tomaremos inicialmente o poema intitulado "Loucura e poesia" (Poemas Reunidos, p. 246) em que a natureza assume o lugar do homem (o sujeito poético) que com ela se funde, de forma dinâmica e intensamente lírica. Eis o poema:

\author{
Furtava as cores de todas as paisagens \\ que colhia. \\ Um dia morreu \\ e um arco-íris bebia \\ seus olhos.
}

Verifica-se neste poema que a poesia de Brasileiro preserva, de forma enfática, os traços de uma linguagem primordial, em que sujeito e objeto (no caso, homem e natureza) se fundem, na realização daquilo que Emil Staiger, no livro Conceitos fundamentais da poética, chama de "um-no-outro", expressão que usa para definir o estado lírico por excelência. Assim, a relação do homem com a sua origem (a natureza) é tão pura e tão plena, que a natureza, agora humanizada, toma de volta o que o poeta dela absorveu: "Um dia morreu / e um arco-íris bebia / seus olhos". O homem, agora morto, é devolvido à natureza não como cadáver, mas como vida eternizada na imagem luminosa e prismática do arco-íris. A brevidade do texto e a simplicidade do enunciado favorecem à criação de um "clima afetivo" que remete a uma relação de intimidade do sujeito poético com a natureza.

O poema "A emenda \& o soneto" (p. 231) traz à tona o recurso do paradoxo (que desnorteia a lógica) e da surpresa, que desconcerta e deixa o leitor rindo e pensando a um só tempo:

\section{O soneto}

Em meio a temporais, saibamos ser

a haste pequenina que se verga.

Pois uma coisa é certa: tudo acaba. 
E o céu ficará limpo como era.

\section{A emenda}

Em meio a temporais, saibamos ser

a haste pequenina que se verga.

Pois uma coisa é certa: tudo acaba.

Não só acaba como não acaba.

Segundo Octavio Paz, ninguém pode escapar da crença no poder mágico das palavras. A poesia de Antonio Brasileiro instaura a magia e o poder da linguagem em perspectivas e dimensões diferentes. Muitas vezes, de forma nua e crua (quando diz, por exemplo, ao final de um de seus poemas, que "um homem é para ser desperdiçado") (p. 105); outras, ainda a título de exemplo, pela encenação de um ambiente afetivo análogo ao do sonho, ou até do delírio. É o que podemos perceber no "Estudo 208", que instaura um ambiente de feições oníricas, em que o domínio do inconsciente nos coloca numa situação de grande solidão e insegurança, pela perda das referências (ausência de memória, entre outras coisas), na medida em que nos retrata como " [...] bailarinos inábeis / executando seus primeiros passos / num palco gigantesco (sem bordas) / sem aplauso - / só nós e uma valsa / sem memória / a ecoar (a ecoar a ecoar) por toda parte / e não há tempo para temer / e não há tempo para chorar [...]".

Já em "Contemplação da nuvem" (p. 112), Brasileiro evidencia um lirismo meditativo, em que a evocação da natureza ("aquela nuvem"), articula leveza de linguagem e profundidade filosófica: "A vida é a contemplação daquela nuvem. / E o mundo / uma forma de passar, que inventamos / para não ver que o mundo não é o mundo, / mas uma nuvem / passando [...]". Aqui, o recurso da repetição sugere um movimento de passagem contínua de tudo, mas sugerindo a noção do retorno, com nos ciclos na natureza. Assim, conteúdo e forma se fundem, produzindo o efeito lírico mais oportuno. 
No texto "ESTUDO 205" (p. 177 a 180), assim como em toda sua obra, o poeta, como já dissemos, revela-se senhor de uma poesia reflexiva e filosófica, que não para de ir em busca dos aspectos obscuros de nossos pequenos e grandes problemas existenciais e desmascara as aparências falsas da vida que não dão paz ao leitor e ao poeta. "O lago é azul e profunda / é minha dor em não saber / ser / mais / e mais profunda é a certeza / e o tino / ( e a límpida manhã que tarda ) e os olhos / da amada triste / e merencória e triste e tão pungente / e triste [...]".

Trata-se de uma poesia purificada pelo sentimento de um eu poético, ampliado pela conexão com o sentimento do mundo. Nesta perspectiva, percebe-se que Antonio Brasileiro é dono de uma poética multidimensional que articula a um só tempo muitos conhecimentos. Algumas imagens na sua poesia são misteriosas, quando não obscuras, a exigir do leitor não preparado dificuldade na experimentação. Como não reconhecer a ironia e o paradoxo que surgem para ocultar a angústia de saber que estar nesta "RODA MíSTICA" (p. 171) é algo efêmero e inútil. "1. Nas asas do pássaro maior / fiz esta ode, perdi-me. / Fôra Deus? Fôra a Demente? / Ai coisas que nos rodeiam / com suas multicolores! / 0. (O mundo é uma bola amarela / envolta num círculo roxo) 1. / Roda, cheia de cores, a roda do destino / com seu comboio de lembranças: / nem amargas nem belas, só lembranças. / A verdade é uma só: são muitas. / E estamos todos certos. E sem rumo." Consta-se, aí, além da dificuldade imposta no âmbito das palavras, uma numeração $(1,0)$ que intensifica a sugestão enigmática do texto. Mas, ao final, através do paradoxo ("A verdade é uma só: são muitas" ), o sujeito poética proporciona ao leitor uma abertura máxima: o reconhecimento das diferentes visões que diferentes sujeitos (e, por extensão, diferentes culturas e momentos históricos) podem apresentar. Subsiste, ao final, graças á maestria do poeta, a incerteza básica que permite a diversidade e impõe ao sujeito a noção clara da limitação de cada maneira de ver o mundo e de conceber a realidade.

Da simplicidade, em todos os sentidos, à obscuridade necessária (isto é, exigida pela complexidade do que poeta deseja expressar), a poesia de Antonio Brasileiro assume uma abrangência surpreendente, como poucos poetas no Brasil, da segunda metade do século XX até o os nossos dias. De poemas breves e altamente sugestivos, como "Poesia e loucura", que consideramos acima, a obras mais extensas e marcadas 
pelo caráter enigmático e pela reflexão filosófica de cunho existencial, como, por exemplo, "Banquete ilúdico" (pp194 / 204), a obra poética desse autor exibe um vasto painel, onde o domínio da linguagem e dos diversos saberes se evidencia de forma plena. 


\section{REFERÊNCIAS}

BOSI, Alfredo. O ser e o tempo da poesia. São Paulo, Cultrix, 1983.

BRASILEIRO, Antonio. Poemas Reunidos. Salvador, Secretaria da Cultura e Turismo, FUNCEB, 2005.

BRASILEIRO, Antonio. Hera 1972-2005. Ed. Fac-similar, Salvador, Fundação Pedro Calmon; Feira de Santana, UEFS Editora, 2010.

BRASILEIRO, Antonio. Da inutilidade da poesia. Feira de Santana, UEFS Editora / 7 Letras.

ELIOT, T.S. A essência da poesia. Rio de Janeiro, Artenova, 1972.

MAY, Rollo. A coragem de criar. $11^{\mathrm{a}}$ ed. Rio de Janeiro, Nova Fronteira, 1982.

PAZ, Octavio. O arco e a Lira. 2o ed. Rio de Janeiro: Nova Fronteira, 1982.

PEREYR, Roberval. A unidade primordial da lírica moderna. $2^{\underline{a}}$ ed. Feira de Santana, UEFS, 2000.

POUND, Ezra. Abc da literatura. 2º ed. São Paulo, Cultrix, 1934. 